\title{
THE (RE)CREATION OF POSTMODERN SPANISH CITIES. THE ROLE OF IMMIGRANTS'
}

\author{
Jesús M. González Pérez \\ Department of Earth Sciences. University of Balearic Islands (Spain) \\ Edifici Guillem Colom. Cra. de Valldemossa, km. 7,5. 07I 22 Palma de Mallorca (SPAIN) \\ e-mail: jesus.gonzalez@uib.es \\ José Somoza Medina \\ Department of Geography. University of León. (Spain) \\ Facultad de Filosofía y Letras. Campus Vegazana. Universidad de León. 2407I León (SPAIN) \\ e-mail: dgejsm@unileon.es
}

\begin{abstract}
The consequences of full incorporation into the European Union and the effects of globalisation contributed to the modification of social structures in Spain. The accelerated rise in immigration has been decisive in creating the post-modern Spanish city. The cities of the twenty-first century are more complex, but also more cosmopolitan, multi-cultural, rich and dynamic.
\end{abstract}

Key words : Post-modernism, immigration, globalisation, multi-culturalism, social exclusion.

\section{GLOBAL CITY - MULTI-CULTURAL CITY IN SPAIN}

The multicultural city has been studied by various authors during the last two decades (Rex, 1988; Cross and Johnson, 1989; Källtorp et al,1997; Ellis and Wright, 1998; Silvey and Lawson 1999; Soja, 2000; Paddison, 2001). In general, the analysed processes have to do with location factors of the different collectives, the integration mechanisms of these groups in the economic system, social problems derived from xenophobic and intolerant attitudes, the formation of new ghettos in the traditional sectors and in the urban periphery or the morphological changes that mark this new reality on our streets. While authors like Muller (2000) enhance the positive aspects of immigration, others focus their investigations in

\footnotetext{
${ }^{1}$ This paper is part of the research project financed by the General Subdirection of Research Projects (General Direction of Research) of the Ministry of Science and Technology (code BSO2001-3302-C02-02), entitled 'Tourism Management of Natural and Cultural Heritage in the Local Development of the Interior of the Balearic Islands'.
} 
demystify the theory of the melting pot (Glazer, 1996; Alba, 2000). In Spain, the arrival of thousands of immigrants is in some ways a new concept and therefore studies on multicultural cities are somewhat scarce (Delgado, 1996; Capel, 1997, 2001; Cebrian and Bodega, 2001; Gonzalez, 2001; Pastor, 2002; Zárate, 2003).

Nevertheless, migratory phenomena have had a notable impact on the demographic characterisation and the social and territorial creation of the different peoples and regions in Spain all throughout modern history. The massive wave of migration from the countryside to urban areas within Spain that began in the 1960's erected cities and exacerbated the rural crisis. The polarised industrial growth that has been taking place since 1960 meant that between 1960 and 1970, municipalities registered a total of 4,260,193 changed residences. During these years, one could already speak of diverse cultures co-existing: authentically Andalusian and Estremaduran neighbourhoods in Barcelona, Galicians in Vizcaya, Asturians in Madrid, etc. Nevertheless, the onset of the foreign-born immigration process is a relatively recent phenomena, although perhaps one with an even greater impact on a society unaccustomed to receiving new populations and cultures, languages and costumes that differ substantially from native ones.

The distribution of the immigrant population is directly related to the level of development, but cities are where the impact of the phenomenon on the landscape can best be perceived. This paper analyses the impact of these new social and national groups on the interior spaces of two very different Spanish cities: the first one situated in the fully emerged space of the Mediterranean and the second the capital of a province in demographic crisis that still has substantial percentages of rural population. Although in varying degrees, modern Spanish cities are also beginning to give the impression of being built on a collage of cultures, individuals, manners and desires. According to the much-debated concept of post-modernism, the immigration process is a key element in the analysis of the latest socio-cultural changes and their relation to the transformation of urban areas in the more dynamic Spanish cities.

Since the 1960s there has been a definite increase in the immigrant population, practically unappreciable in so far as numbers, but that has contributed to the economic development in very localized spaces including the mineral river basins or zones with extensive agriculture. However, in the last ten years there have been changes of great magnitude where the most populous cities such as Madrid or Barcelona truly have immigrant neighbourhoods such as Chinese, Latin American, Sub-Saharan, Margraves or Romanians, where the population concentration process runs the risk of converting large urban sectors into differentiated ghettos. In both cities, this phenomenon occurs mainly in the degraded historical centres, in marginal zones that were middle class in the 50s and 60s, and in traditional nuclei of the urban outskirts. In all of them, the multicultural city is found on the streets, in public plazas, in parks, in malls, and in the everyday life on the commute to work.

In our days, global issues are made local issues for the large enterprise and financial corporations that can disassemble its production systems to localize each phase of manufacturing and commercialisation of a product in different parts of the world, while at the same time diversifying their economic. But in the same way, local things become global 
things. The increase in people's mobility and the ease in settling where there is a real demand for workers allows that in certain cities we can go from one country or even continent to another by simply crossing the street, that we hear radio stations or watch television stations in another language without having to change the antenna, or that on any bench in the neighbourhood park some people are reading newspapers from left to right, right to left, down to up, up to down even though they all came from the same printer.

What is true is that until recently most studies in Spain only included Madrid and Barcelona on the list of cities in the globalisation process while the recent evolution shows that today there are many nuclei with examples similar to those above. What would Queen Isabel and King Ferdinand say if they saw the highway signs in Andalucia written in Arabic?

\section{THE ROLE OF IMMIGRATION IN POST-TRANSITION SPANISH DEMOGRAPHICS}

Until the 1980's, migration in Spain was studied almost exclusively from the perspective of demographic loss. Economic progress and the new socio-political system turned Spain into a host country for growing masses of population. From 1975 to 1990, immigration came predominantly from Western Europe, to which the return of Spanish emigrants must be added (approximately 500,000 emigrants returned between 1975 and 1990). From 1990 on, the greatest boom in work-related immigration took place, almost exclusive at first by contingents of North Africans and Latin Americans. Progressively, immigrant group origins began to diversify as a result of the growing globalisation of the migratory. The immediate result was the new direction that geo-demographic analysis took.

Immigration in Spain is a extremely interesting issue, among other questions, because Third World inhabitants who are attracted to Spain for economic reasons are added to large numbers of well-off Europeans who consider the Mediterranean shores an attractive place in which to establish their main residence or second home. The number of immigrants in Spain has grown an average of approximately $10 \%$ per year from 1975 to the present. The figure of 165,289 foreigners with residence status in 1975 reached 1,448,671 in 2003 (30 June), to which must be added over 125,000 persons who obtained Spanish nationality and an indeterminate number of foreigners living in irregular and clandestine situations, estimated at over 300,000. Although official Spanish figures do not reflect this ${ }^{2}$, we can speak of two million foreign residents in a total population that has recently surpassed forty one million, a percentage therefore of $5 \%$ equivalent to the European average ${ }^{3}$.

\footnotetext{
${ }^{2}$ The latest officials statistics of 2003 show that $3.54 \%$ of the resident population in Spain are foreigners with resident status

${ }^{3}$ According to the National Municipal Register at January 2002 the figure of foreigners belonged to 1,977,944 people. This quantity includes the foreigners that have residence permission and to those that have arrived in Spain with tourists' card, although most of them uses this strategy to facilitate its entrance in the country.
} 
Tabel 1. Principals foreign residents in Spain in 2003.

\begin{tabular}{|l|r|r|l|l|l|l|l|l|}
\hline Nationality & \multicolumn{1}{|l|}{ Total } & $\mathbf{( \% )}$ & Nationality & Total & $\mathbf{( \% )}$ & Nationality & Total & $(\mathbf{\%})$ \\
\hline Morocco & 263,174 & 20.22 & Italy & 39,258 & 3.02 & Ukraine & 16,606 & 1.28 \\
\hline Ecuador & 132,628 & 10.19 & Romania & 38,855 & 2.99 & Bulgaria & 16,108 & 1.24 \\
\hline Colombia & 81,709 & 6.28 & Peru & 37,863 & 2.91 & Philippines & 15,417 & 1.18 \\
\hline U. K. & 81,685 & 6.28 & Dominic. R. & 31,584 & 2.43 & Pakistan & 14,410 & 1.08 \\
\hline Germany & 62,332 & 4.79 & Argentina & 26,248 & 2.02 & U.S.A. & 14,028 & 1.06 \\
\hline France & 45,303 & 3.48 & Cuba & 23,605 & 1.81 & Belgium & 13,611 & 1.03 \\
\hline Portugal & 42,648 & 3.28 & Algeria & 18,380 & 1.41 & Senegal & 13,428 & 1.01 \\
\hline China & 42,578 & 3.27 & Netherlands & 17,324 & 1.33 & Brazil & 13,061 & 0.98 \\
\hline
\end{tabular}

Source: 2002, Foreign and Immigrant Bureau

After the regularisation process of 1991, immigration from all parts of the world escalated notably. Together with Italy and Germany, Spain has been one of the European countries experiencing the sharpest growth in foreign population in the last decade. Since 1990, Spain's full economic integration into international capitalism and the consequent increased demand for unskilled labour have progressively balanced the distribution of nationalities between northern and southern countries. Thus, the sustained rise in the number of European residents from more highly-developed countries who choose to settle in Spain does not compensate for the spectacular growth in the number of Africans and Latin-Americans who flee from misery. In $199250,23 \%$ of the foreigners with residence permission was European, in 2003 only 34,98. Although Morocco heads the list by far of countries with the most immigrants in recent years, there has been a spectacular and significant rise in the number of immigrants from Ecuador and Colombia.

With a natality and fecundity in frank setback, the immigration is the only solution in a society that is expanding, to the point that without it the future of the Spanish population would be characterised by demographic stagnation and an ageing population. Despite the fact that Spain, together with Italy, is the country with the lowest birth rate in the European Union at present, the recent rise in fertility after a decade of decline is due to the high birth rate of immigrant women, mainly from North Africa (Morocco) and South America (Ecuador and Colombia). The birth rate for foreign women has climbed $76.4 \%$ since 2000 and accounted for $10.4 \%$ of total births in 2002 .

\section{IMMIGRANTS IN THE POSTMODERN CITY}

The distribution of immigration in the territory is a clearly geographic question which we shall attempt to approach by analysing various scales: province, municipality and, especially, inner city. Regardless of whether immigrants come from the Third World or from opulent Europe, location on the regional or provincial scale is closely related to more highlydeveloped areas. In the inner city we see a marked distribution of immigration according to origin and social status. 


\section{Emerging territories. Regional contextualisation}

Like the rest of Europe, Spain will have the immigration it needs in function of its development and not according to what is marked by the almost always conflictive immigration policies. Since 1970, the distribution of immigration has been concentrated in the largest metropolitan areas and increasingly, in the Mediterranean coastal fringe and the Islands (Lora-Tamayo, 1997). On the one hand, the big cities and main tourist areas are the places which most attract migrants in search of work, as the chances of finding jobs increase considerably in these areas in the construction sector, domestic service, hotel and catering industry, etc. Demand is great for seasonal workers in the highly-productive, labour-intensive and irrigation-based agriculture sector that inescapably requires foreign labour in the regions that extend from the French border to Gibraltar and include the Balearic and Canary Islands. On the other hand, the considerable presence of Europeans with medium and high purchasing power, primarily made up of retired seniors, can also be found on the Mediterranean shores as well as in the Canary Islands, but in this case, in search of beaches and a year-round benign climate. The consequences, both economic (consumption, housing, residential complexes...) and social (associations, newspapers, personal services...) of this growing mass of retired seniors has led to troubled social relationships with the native population, although to a lesser degree than job-based immigration does. We cannot speak of racism in this case, given that these social conflicts are attenuated when compared to conflicts involving immigrants from poorer countries. Despite the diversification of destinations, the provinces of Madrid (291.866 foreign inhabitants) and Barcelona (235.188) welcome to $39,88 \%$ of the immigrants in 2002 .

Figure 1: Distribution of foreign residents by province in 2002.

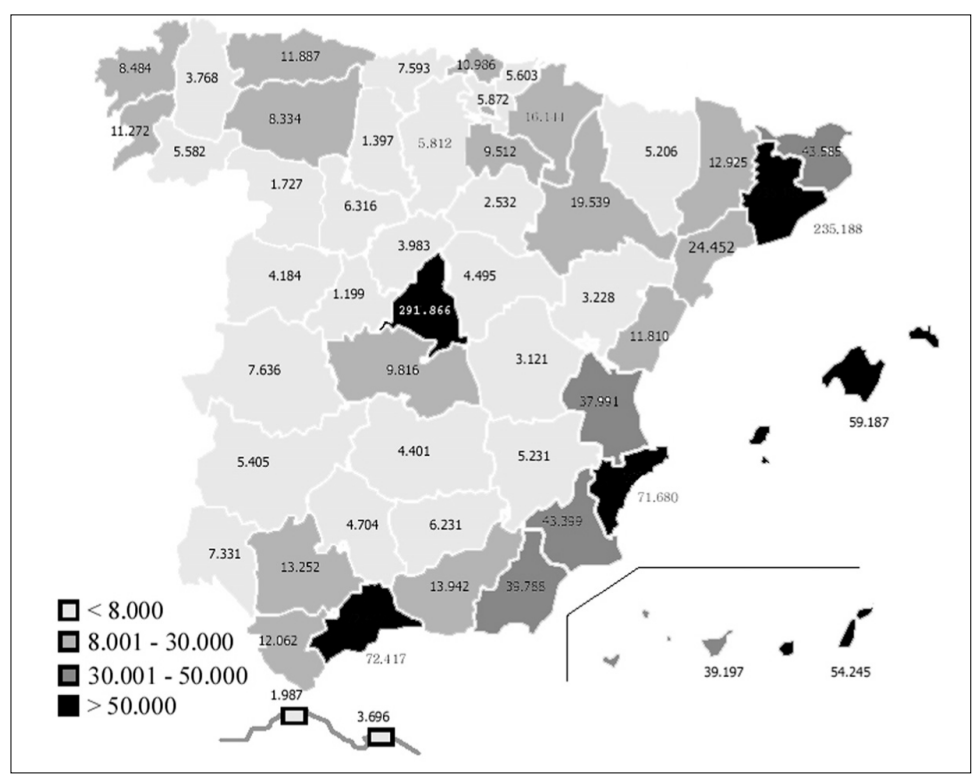

Source: 2002, Foreign and Immigrant Bureau 
Conclusions on the distribution model of foreign-born residents by province cannot always be extrapolated to analysis on the intra-regional scale. Foreigners represent $8.40 \%$ of the total population of the Balearic Islands in 2001, well above the national average, but also above the European Community average as well. The marked specialisation in tourism make these islands appealing places for well-off Europeans to establish their permanent residence in. Thus, 43,411 foreigners from the European Union reside in a reduced area of less than $5000 \mathrm{~km} 2$. Although these immigrants are predominantly pensioners or renters, due to the penetration of foreign capital from multi-national companies, there also large numbers of managers and employees working in hotel chains, tour operators, real estate agencies and even as tourist guides. Furthermore, although difficult to quantify, there are numerous businessmen and professionals, particularly Germans, who own second homes and spend half the year in their Mediterranean residence.

Figure 2: Foreign population in the Balearic Islands by municipality.

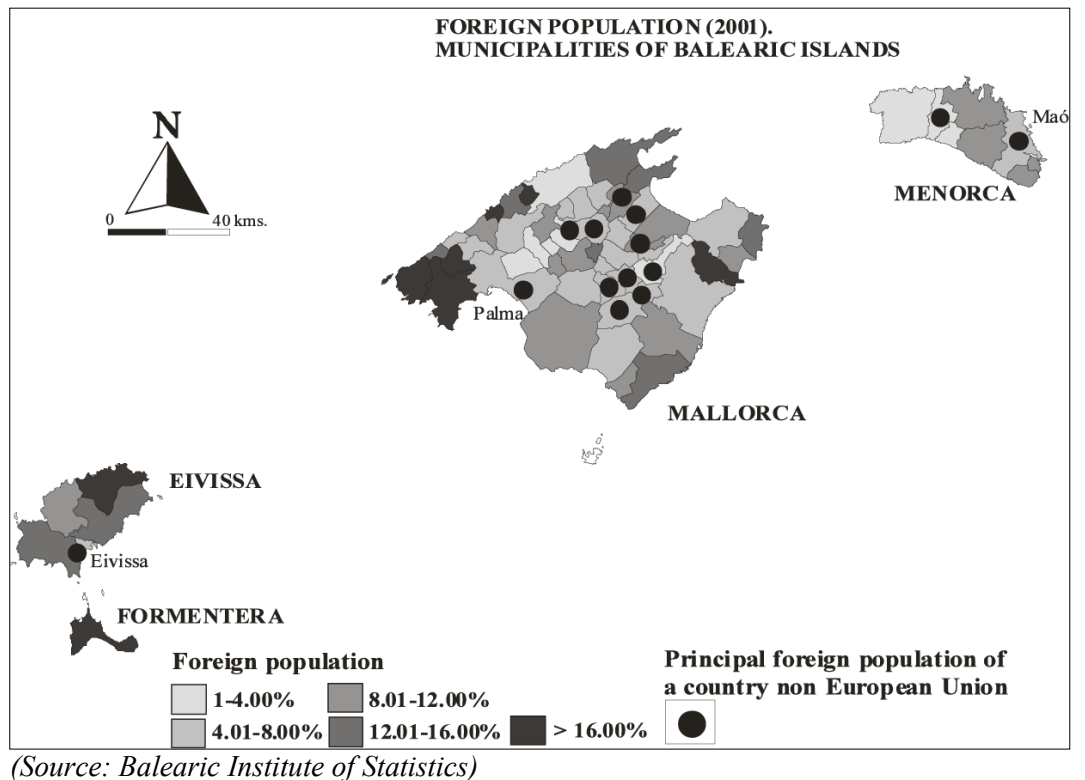

The fact that rural and coastline landscapes strongly appeal to immigrants from the European Union means that in comparison to other Spanish regions, cities are relatively less attractive to foreigners. Nevertheless, there is a duality of behaviours according to whether urban or rural spaces are being analysed. Natives from the European Union are the largest group of foreigners in the islands overall, in coastal tourist municipalities and the less agricultural areas of the interior. Well-off Europeans show a predilection for non-urban spaces. However, immigrants from the rest of the world (especially Africans and Latin Americans) are the non-Spanish majority in two types of municipalities: main cities (Palma, Maó, Eivissa and Inca) and those rural villages with an important agriculture sector. 
Figure 3: Foreign density in Castile and León.

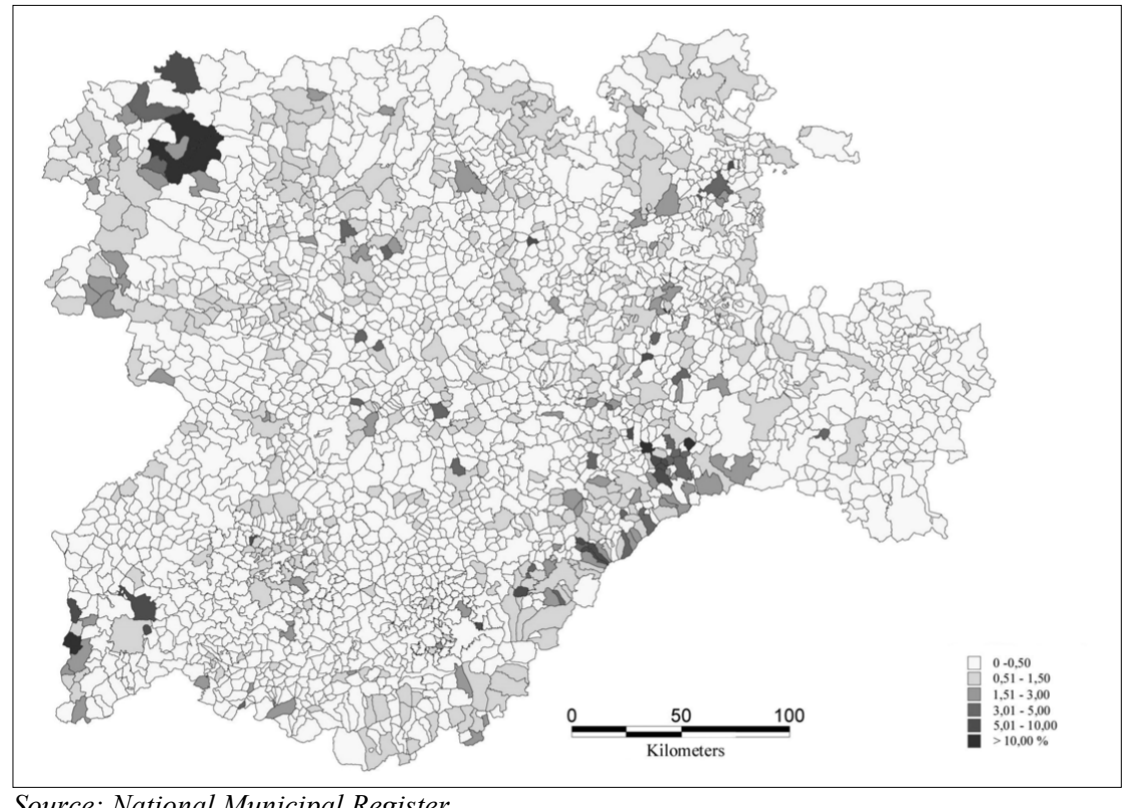

Source: National Municipal Register

As far as Castile and León, an Autonomous Community in the interior of Spain with a much less dynamic economy yet a territory 19 times as large as the Balearic Islands, the 35,954 foreign residents in 2003 were spread out very irregularly throughout the territory. Looking at the map (Figure 3) we can create four explicatory syntheses of great interest. First, the graphic shows that the overall majority of the municipalities have a very small percentage or do not count at all on foreign population amongst its inhabitants. For the most part they are rural municipalities defined by a decrease in population, scarce possibilities of economic development, where the few examples of foreign immigrants find work in the agricultural sector. Secondly, the provincial capitals maintain themselves as small islands where the foreign population assumes a slightly greater percentage. Here there are nine mid-sized cities with populations between 50,000 and 300,000 with some economic development that allows a reduced number of immigrants but never more than $5 \%$ of the total population. Thirdly, in the upper portion of the graphic, there are a series of municipalities that from north to south have the four mineral river basins of the region, although in actuality the only one that is fully functional is the one situated furthest to the west, exactly where the greatest percentage is of Castile and León. After the fuel crisis of 1973 and the appearance of carbon production, thousands of foreign workers from Cape Green, Pakistan, and Portugal found work in the mines. When they closed, many returned to their countries, others settled in the closest cities, and a larger percentage settled right where they had been living. Lastly, in the southeast sector there is another space where a series of municipalities with a large immigrant population is evident. It is not directly related with Castile and León but with the Autonomous Community located on the other side of this region, Madrid. 


\section{Case studies: Palma de Mallorca and León}

The different levels of socio-economic development and functional specialisations of these two cities, one situated in the interior of Spain and the other set in the Mediterranean sea, mean that each needs immigrant participation in the territorial and social creation of the city in varying degrees. Be that as it may, from the middle of the 90's on, both cities have experienced migratory influxes that have created demographic behaviours and urban landscape behaviours that were unknown just a few years previously.

Palma is a multi-cultural city enriched by diversity. In contrast to a homogeneity defended by the most reactionary groups in society, the effects of globalisation on a tourist economy as specialised as the Balearic economy is, along with the associated accelerated urban building process, has resulted in a city that embraces a large diversity of cultures and ethnicities. In the Balearic Islands, endogamy and the difficult communications with other territories that for decades characterised many island spaces was brusquely inverted in the middle of the twentieth century. The 'touristisation' process, which took off in the 1950's, also had a number of effects on the Islands' capital, Palma de Mallorca. Urban growth developed quickly from 1960 onwards, as can be seen in the countless apartment blocks built to house the growing masses of Spanish immigrants from the peninsula who came to work in the thriving construction and hotel sectors. Although labour force immigrants were exclusively Spanish (Andalusians, Murcians, etc.) during those early years, the first welloff Europeans began to establish themselves permanently in tourist neighbourhoods with higher-quality architecture along the coastline. As a result, the period of greatest urban and demographic growth in Palma was based on radical models of social exclusion. Earlier than other Spanish cities with higher populations, the characteristics of foreign-born residents shaped the map of Palma and endowed it with a singular social characterisation and territorialisation. Just when the descendants of the mass of Spanish immigrants had fully integrated into Balearic society, immigration currents from Third World countries intensified. All this diversity of migratory movement has generated a new city with serious segregation problems, but also with interesting dynamics and levels of cultural co-existence. In 2002, 41,743 foreign workers registered with the Social Security system, the highest number in history. In 1996, just a few years before, only eight workers had registered. The latest data from January 2003 reveals a total population of 373,043 in Palma. Of these, only $46.42 \%$ were born in the city itself. $30.11 \%$ come from other Spanish provinces and $14.9 \%$ is foreign-born.

The impact immigrants have on Palma is produced by the double south-north and northsouth influx. Its significance lies less in numerical quantification, but rather especially in the great diversity of origins and socio-economic levels. As in studies of other cities (Sassen, 1986; Darden, 1987; Pacione, 1996), spatial concentrations of ethnic minorities in specific neighbourhoods can be seen in Palma throughout the city. Spatial segregation accelerates and intensifies social, economic and cultural discrimination based on ethnic and cultural characteristics. This inequality stems from a double cause. First, economic inequality and proximity to the workplace, to a lesser degree, lead to discriminatory practices in accessing the housing market. Secondly, Third World immigrants concentrate in neighbourhoods 
where rented housing is cheapest, to the point where minute social networks are formed that attempt to attract other fellow countrymen in turn, in order to obtain protection from the aggressiveness emanating from outside.

The spatial model of urban ethnic segregation in Palma is similar to the European model, as diversity predominates in both. There are up to 130 groups of different cultural origin in Palma sharing the territory with the native population. Foreign population accounts for over $20 \%$ of the total population in fifteen statistical areas of Palma. $42.55 \%$ of the residents of Cala Major (a neighbourhood on the seafront) are immigrants. Although the distribution of immigrants varies according to nationality, for different reasons, the greatest range of nationalities is concentrated in the old (historic) city. The more dilapidated neighbourhoods of the old walled city continue to be the port of entry for many job-seeking immigrants, while neighbourhoods that have been rehabilitated and revitalised attract foreign residents with higher economic levels. One negative aspect of this is that immigration is causing the historic city to show worrying signs of social segregation. Co-existence is complex to the point where, under the pretext of rehabilitation, aggressive urban renewal policies are being carried out in the El Sindicat (Sa Gerreria) area which results in the expulsion of many of these minorities from their housing with the unconditional approval of local society.

The typical European Union immigrant shares the economic and social conditions of the 3,000 Germans who have established their habitual residence in Palma. In general, they are well-off groups of professionals, qualified workers in service companies and retired persons. Their location depends less on economic variables than on the quality of the landscape setting. Although present in almost all the statistical areas, they account for high proportions of the rehabilitated quarter of the old city, high-quality tourist neighbourhoods on the eastern coastline, suburban areas with substantial residential growth in the western section of the municipality, statistically urban areas in the north and certain neighbourhoods to the east that lie close to the main German tourist area (S'Arenal). The ensanche of population (neighbourhoods outlying the old city; extension urban area built-up since the 1900 's) and the periphery are not in great demand by central Europeans. In Les Maravelles (southeast coast), 9.15\% of the population of is German.

Although the types of neighbourhoods where Ecuadorians and Moroccans have settled are similar on the whole, on few occasions do high proportions of these two nationalities coincide in the same statistical area, with the exception of co-existence in the severely dilapidated neighbourhood of El Sindicat. The less valuable areas of the historic city and the ensanche have the highest percentages of Ecuadorians and Moroccans. With few exceptions and in contrast to what is taking place in French cities, housing complexes located in neighbourhoods around the periphery are not inhabited by Third World immigrants, but predominantly by immigrants from less-developed areas in the south of Spain. The intensively exploited and more run-down tourist areas in the Bay of Palma house equally large numbers of immigrants who seek jobs in the hotel industry and domestic service during the high summer season. The most significant statistical concentration of Ecuadorians is in El Sindicat (6.94\% of the total population) and Moroccans in Sant Jaume (7.14\%). The latter area is also situated within the old walled city. 
Figure 4: Foreign population in statistical zones in Palma de Mallorca

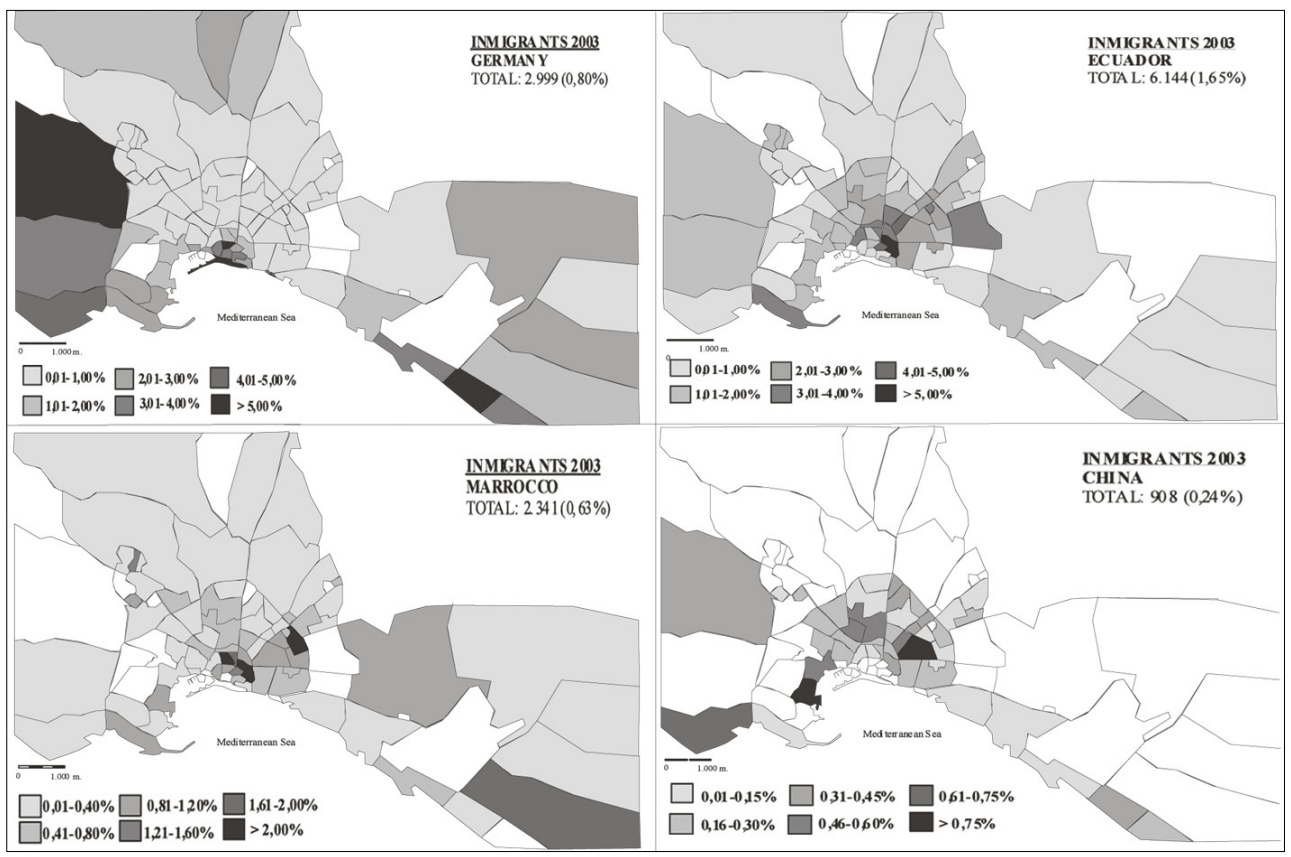

Fuente: City Council of Palma de Mallorca

Lastly, although the Chinese population is still not too numerous in the city overall, a study of the community is interesting, because of both the growth it has undergone in recent years, as well as its direct participation in creating new urban landscapes, especially those associated to the development of important restaurant and retail commerce activities. The distribution of the Chinese immigrant population in Palma is limited almost exclusively to the ensanche, a densely-populated urban network with the presence of still-important small neighbourhood businesses. In contrast to other immigrant workers, the majority do not wish to live in the old city. The Chinese account for a relatively high and significant percentage of residents in the working-class neighbourhoods of Pere Garau $(0.83 \%)$ and especially El Terreno $(1.10 \%)$. Situated on the seafront, El Terreno is an old tourist neighbourhood in Palma which at present displays serious signs of physical and social decay. The location of numerous restaurants and businesses run by the Chinese population and aimed at low-quality tourism explains this demographic concentration.

In León, with a population of 144,259 as of July 2003 , only 3,732 or $2.59 \%$ were born outside of Spain. Just as we demonstrated the key interpretations of the dynamic region, in the analysed cities, we clearly observe the influence of the number of immigrants on the economic development. The factors that have tourism bear extraordinary importance to sustain the economic level of the Illes, explain the elevated number of European residents as well as the non-European immigrants. However, in León neither the climate nor the Spanish tourism nor any other sector exert as much influence in investment attraction as do 
numerous job opportunities and a general enhancement in the way of life. The few opportunities to find work minimize the attraction of this city for immigrants. Those who live in the city work in positions that the Spaniards reject, but this situation is not very common, and it is unable to sustain the growing avalanche of immigrants. For this same reason it does not produce. León, 300 kilometers from Madrid, is experiencing a slight growth in its foreign population while other locations a bit further but with greater economic development and therefore opportunities for work see their numbers of immigrants increase rapidly.

Figure 5: Foreign population in statistical sections in León.

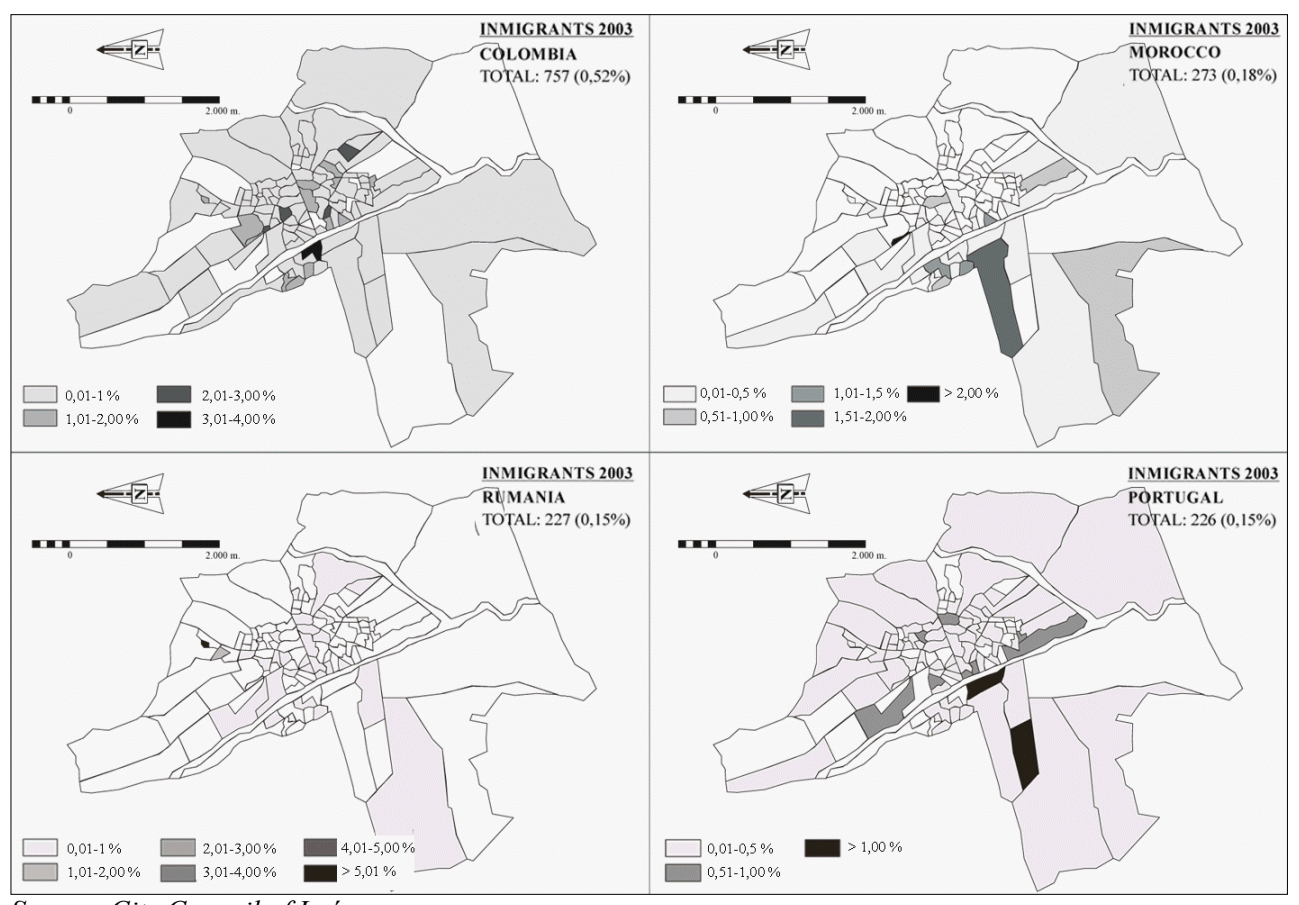

Source: City Council of León

Among the 117 statistical sections that make up León, only one of them had in 2003 a foreign population greater than $10 \%$ (144 immigrants that were $13.56 \%$ ), and it does not correspond to one of the sectors of historical importance, but with the most run down section of the city, a neighbourhood created during the 1950s through the initiative of a bishop to house the poor people of León. This neighbourhood of the Inmaculada is within the figure that shows the distribution of the four main groups of immigrants where $40 \%$ of the residents are of Romanian origin ( $8 \%$ of the inhabitants of the neighbourhood.) The Colombian population is the most plentiful, although only 757 people or $0.52 \%$ of the total, are registered. Their localization patterns on the city draw a series of key points as much in the historical centre as in the traditional neighbourhoods and especially in some regions West of the river described as being worker neighbourhoods on the decline. The Moroccan population 
is not as spread out but its low number, 273 people $(0.18 \%)$ impedes this concentration from being reflected in the global densities. Within this group, made up mostly of males between the ages of 30 and 40 , seven sections form $50 \%$ of its inhabitants, always situated on the outskirts of the city. Lastly, the Portuguese population is the most abundant coming from the European Union, and their distribution is much more evenly spread out throughout the city.

Corporate buildings and immigrant communities are the two extreme modalities that appropriate and form urban spaces in the main cities of the developed world (Sassen, 1996). The roles of immigrants are related to the development of an informal economy that nevertheless originates in the lack of both opportunities and demand for labour and products by society as a whole. The urban landscape, made up of physical elements and social components, reflects an interesting amalgam of cultures, sounds, colours and languages in the two analysed cities. Its influences extend to public and private areas and can be best observed in businesses catering to the immigrants themselves (ethnic restaurants, hairdressers, grocery shops, clothing shops, etc.) and services designed to cover their needs (internet and telephone booths and businesses remitting money abroad), which are also usually run by immigrants. Because of the everyday nature of these activities, they are found near areas predominantly populated by immigrants (the non-tourist old city and ensanche of population). In Palma we begin to perceive the interesting replacement of traditional retailers with other immigrant retailers of a new stamp through a process of functional invasion-succession, a process that is taking place in other historical Spanish cities. The very frequent use of collective public spaces by immigrants approaches the point of appropriation. The black subSaharan and Moroccan population socially and culturally enrich Plaza de España and Parque de las Estaciones, both of which are situated in the city centre. Africans and LatinAmericans populate Paseo Maritimo during their time off, especially on weekends. In Leon, the presence of Latin Americans it is appreciated in the Park of Quevedo and that of immigrants from the Oriental Europe around the Church of The Sales, near to the neighbourhood of the Immaculate. Nevertheless, in some cases, the cultural, ethnic and linguistic diversity of newly-arrived immigrants leads to collective conflicts and tensions between groups. Multi-culturalism causes many residents to lose their identification with their neighbourhood, which leads to feelings of insecurity. The dilapidated part of the historic city is a good example in the study of conflicts that irremediably conclude in the increasing social exclusion of minorities. The population of Palma itself, which is progressively leaving the old city, encourages dilapidated housing to be torn down, under the cover of an integral urban renewal policy. Palma residents consider that they are thus not only cleaning and renewing ample central spaces but also expelling a foreign population that is appropriating their old city. Nevertheless it is of concern that European Union immigrants, especially Germans, are the most warmly received group of immigrants, although they are not received without a degree of resentment. The role the economic component plays in the perception of foreigners is fundamental in determining the degree of acceptance by the native population. This demonstrates that segregation has a fundamental social basis in function of income level and that notions of culture and ethnicity are secondary. 


\section{CONCLUSIONS}

The abundant migratory influxes from non-Spanish origins to urban agglomerations is one more manifestation of globalisation and the phenomena that accompanies it: transformation of the production system, expanding new technologies, development of Post-Fordist capitalism, mobile population at the planetary level, birth of a new international order, etc. (Zárate, 2003). Despite the distance that separates us from other, more highly-developed European countries, at present we can affirm that the Spanish population is evolving towards ethnic plurality and multi-culturalism.

The School of Urban Ecology of Chicago has demonstrated that cities are created by populations of all conditions, from all parts of the world, that fights to find its space in the urban habitat. Cities have been a place for co-existence (peaceful and conflictive), social mobility and crossbreeding all throughout history. Heterogeneity and the mix of social forms in the city are not only possible, but healthy and even structurally strategic (Delgado, 1996). The growing cultural and economic power of immigrants is building a new type of metropolis, unknown in Spanish cities. The city of Palma is a clear example of the urban growth that has resulted from immigration of Spanish origin in the 1960's, and from all over the world, since 1990. The changes in demographics, use of land and social dynamics are evident proof of vitality in a city that is increasingly cosmopolitan. León, on the other hand, still shows a scarce presence of foreign immigrants, chord with his smallest economic dynamism, although every time is more frequent to listen in the daily walks to people's groups speaking in different languages.

\section{References}

Alba, R. D., 2000: Assimilation's Quiet Tide. V: Steinberg, S. (editor), Race and ethnicity in the United States. Massachusetts, Blackwell, p. 211-222.

Capel, H., 1997: Los inmigrantes en la ciudad. Scripta Nova, 3, p. 1-25.

Capel, H., 2001: Inmigrantes extranjeros en España. El derecho a la movilidad y los conflictos de la adaptación: grandes expectativas y duras realidades. Scripta Nova, 81, p. 1-32.

Cebrián, J.A., Bodega, Mª., 2000 : Solidaridad y ciudadanía: los inmigrantes en la España de hoy. V: Vivir la diversidad en España. AGE, Madrid, p. 107-124

Cross, M. Johnson, M., 1989: Race and the Urban System. Cambridge. Cambridge University Press.

Darden, J. et al, 1987: Detroit: Race and Uneven Development. Philadelphia, Temple University Press.

Delgado, M., 1996: Qui pot ser "inmigrant" a la ciutat?. V: Ciutat i inmigració, Centre de Cultura Contemporània de Barcelona, Barcelona, p. 1-5.

Ellis, M., Wright, R., 1998: The Balkanization Metaphor in the Analysis of U.S. Inmigration. Annals of the Association of American Geographers, 88 (4), p. 686-698

González, J.M., 2001: Formación de la trama urbana y transformaciones sociales recientes en la ciudad de Palma de Mallorca (1960-2001). Geographicalia, 40, p. 75-100. 
Glazer, N., 1996: Multiculturalism and American Exceptionalism. V: City and inmigration, Centre de Cultura Contemporània de Barcelona, Barcelona, p. 1-8.

Källtorp, O. Elander, I., Ericsson, O.,, 1997: Cities in transformation-Transformation in cities. Aldershot, Ashgate

López Trigal, L., 2000: La diversidad e integración de la inmigración extranjera en España. V: Vivir la diversidad en España. AGE, Madrid, p. 157-174.

Lora-Tamayo, G., 1997: La inmigración extranjera en España. Cuadernos de Formación, 9, p. 12-32.

Muller, T., 2000: The Inmigrant Contribution to the Revitalization of Cities. V: Steinberg, S. (editor), Race and ethnicity in the United States. Massachusetts, Blackwell, p. 234-252.

Pacione, M., 1996: Ethnic segregation in the European city. The case of Vienna. Geography, 81 (2), p. 120-132.

Paddison, R., 2001: Communities in the city. V: Paddison, R. (ed.), Handbook of U. Studies. London, SAGE, p. 194-205

Pastor, L.J., 2002: Globalización y migraciones hoy: una perspectiva española en el marco de la Unión Europea. V: Pastor, L.J. (coord.), Globalización y migraciones hoy: diez años de continuos desafíos. Univ. de Valladolid, Valladolid, p. 9-18.

Rex, J. 1988: The Guetto and the Underclass: Essays on Race and Social Policy. Aldershot, Gower.

Sassen, S., 1986: New York City: economic restructuring and inmigration. Development and change, 17, p. 85-119

Sassen, S., 1996: Ethnicity and space in the global city: a new frontier?. V: City and inmigration, Centre de Cultura Contemporània de Barcelona, Barcelona, p. 1-9.

Silvey, R., Lawson, V., 1999: Placing the Migrant. Annals of the Association of American Geographers, 89 (1), p. 121-132

Soja, E., 2000: Postmetropolis. Critical studies of Cities and Regions. London, Blackwell.

Zárate, M.A., 2003: Manifestaciones de la multiculturalidad en el centro de Madrid. V: López Trigal, L., Relea, C.E., Somoza, J., (coord.), La ciudad. Nuevos procesos, nuevas respuestas. Universidad de León, León, p. 399-407. 